\title{
Reserve and resource assessment of Li-rich geothermal brines in Europe
}

\author{
ROMAIN MILLOT ${ }^{1}$, BLANDINE GOURCEROL ${ }^{1}$, BERNARD \\ SANJUAN $^{1}$, ELODIE JEANDEL ${ }^{2}$, DETLEV RETTENMAIER ${ }^{2}$, \\ SOPHIE LEBOUIL ${ }^{3}$ \\ ${ }^{1}$ BRGM - French Geological Survey, Orléans, France \\ ${ }^{2}$ EIfER - European Institute for Energy Research, Karlsruhe, \\ Germany \\ ${ }^{3}$ ERAMET, Trappes, France
}

The EU "Green Deal" aims to address climate changes and related techno-economic issues. In this specific context, innovative investigations for raw materials are needed for the energy transition. The European project EuGeLi (European Geothermal Lithium brines) aims to supply Europe with lithium, which is a strategic metal for Li-ion battery manufacturing. A direct extraction process to valorize lithium is developed to extract this latter from European brine located in Alsace, at the French/German border. The benefit of this project is to implement the Eramet \& IFPEN patented extraction system on existing geothermal well facilities avoiding thus the opening of new surface mines or the drilling of new wells.

In this project, one of the objective is to characterize $\mathrm{Li}$ rich geothermal brines in Europe and assess their Lienrichment through the review of state of the art in the literature for geothermal brines. This review addresses main characteristics of geothermal brines in terms of lithium concentrations, geothermal discharge water flows, accessibility of wells or springs, fluid salinity and chemical composition (major cations and anions), trace elements levels and geological setting (hydrogeology, lithology, geothermometry and water/rock interaction intensity).

The main goal of this project is to contribute to the fundamental understanding of the natural processes related to $\mathrm{Li}$ endowment in geothermal brines, by the synthesis of geochemical and hydrological data in the context of Li-rich geothermal brines. We have explored the various Li sources using existing geological data, statistical approaches (agglomerative hierarchical clustering of elements, exploratory statistical methods such as principal component analysis - PCA, linear discriminant analysis - LDA), and use of $\mathrm{Li}, \mathrm{Sr}$ and $\mathrm{B}$ isotopes to better describe the different mechanisms of Li-enrichment in European geothermal brines. The main results will be discussed at the Conference. 